\title{
Smart Microfluidics: The Role of Stimuli- Responsive Polymers in Microfluidic Devices
}

\author{
Simona Argentiere ${ }^{1}$, Giuseppe Gigli², Mariangela Mortato ${ }^{3}$, \\ Irini Gerges ${ }^{1}$ and Laura Blasi ${ }^{4}$ \\ ${ }^{1}$ Fondazione Filarete Srl, Viale Ortles, Milano, \\ ${ }^{2}$ Dipartimento di Ingegneria dell'Innovazione, \\ Universita del Salento, Lecce, \\ ${ }^{3}$ Superior School ISUFI, Università del Salento, Lecce, \\ ${ }^{4}$ Nanoscience Institute of CNR, Lecce, \\ Italy
}

\section{Introduction}

\subsection{The emerging market of lab-on-chip microfluidics}

Microfluidic technologies actually represent one of the most expanding fields in the market of commercial instruments. With an estimated world market of about 3 billion dollars in the year 2014, (www.yole.fr/) it is clear that microfluidic devices will continue to find new applications, and to generate interest from a wide range of industries and research fields.

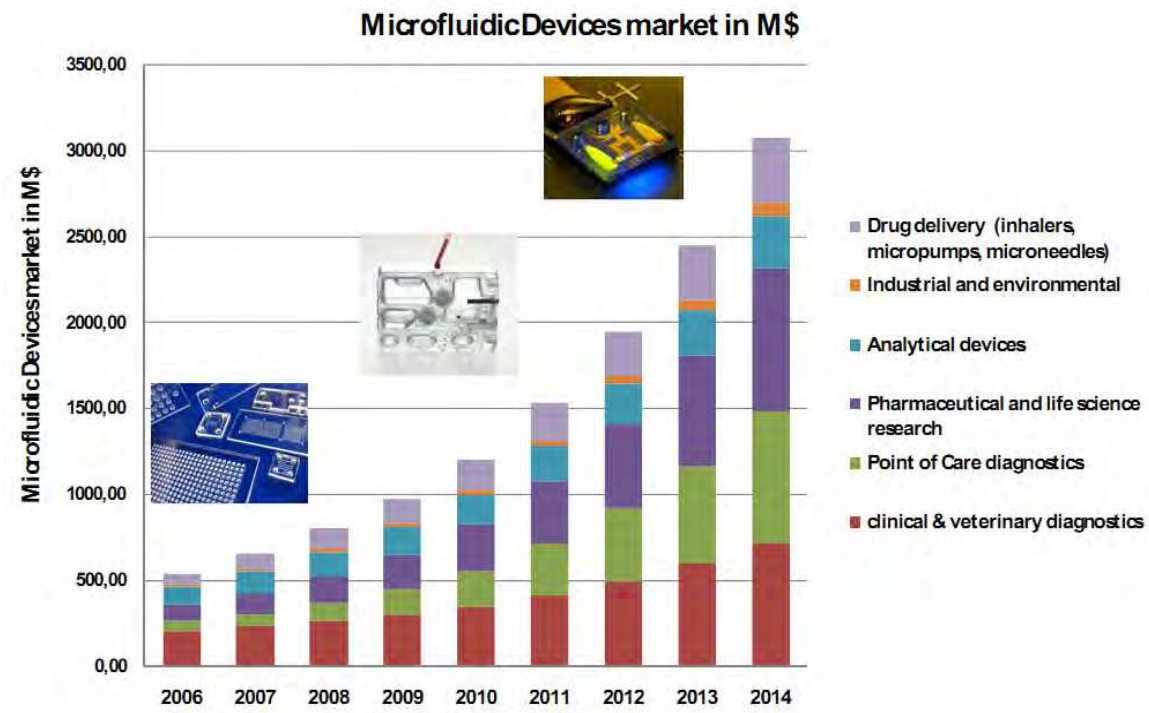

Fig. 1. Trend in microfluidics market. Reprinted from http://www.yole.fr/. 
The past few years have seen rapid growth within the microfluidics field, whose applications include pharmaceuticals, life sciences, biotechnology, industry, environment and agriculture. The applications of microfluidics in food, agriculture and biosystems have been recently reviewed.(Neethirajan et al., 2011) However, the market of microfluidics in the life sciences is considered to possess by far the greatest potential in terms of products and commercial outlets, and is markedly increased in the last years. Accordingly, most efforts by both academic groups and private companies have been focused on the development of microfluidic devices for point-of-care (POC) diagnostics, biosensors and cell biology.

Microfluidics covers a set of multidisciplinary technologies such as physics, chemistry, engineering and biotechnology that deal with the development of miniaturized devices to manipulate and process minute volumes of fluids. Essentially, a 'lab on a chip' is a microfluidic device comprising tiny channels and components (i.e., few to hundreds of micrometres) connected to liquid reservoirs that control the flow of nano-/pico-liters of liquids. The intrinsic features of microfluidic devices ensure low consumption of reagents and sample for each process, and rapid and repeatable analysis.(Sia \& Kricka, 2008) Indeed, the increased surface-to-volume ratio in microfluidic channels shortens reaction times, and make the reactions more accurate and effective, whereas microfluidic chambers and channels measure volumes more consistently than human hands can, thus reducing error rates.(Beebe et al, 2002; Dittrich \& Manz, 2006) Microfluidics technologies can be also easily automated to do routine assay and sample preparation, with the advantages of highthroughput assays, multistage automation, and parallel processing of multiple analytes.(Beebe et al, 2002) Finally, unlike conventional equipment, these miniaturized systems possess the dimensions and volume handling capacities to manipulate and sample single cells, which make them particularly attractive for biomedical applications.(Kim et al, 2008)

\subsection{The need for highly integrated LOC devices: The new challenge in microfluidics}

To date, extensive biological and chemical tasks are currently required outside the microfluidic devices to prepare and pre-process samples prior to their detection.

These tasks include sampling, pre-concentration, fluorescence labelling, filtration, mixing, reaction modules (for example, different heating zones), and analytes purification. Further, they usually involve high consumption of sample and expensive reagents, and require both instruments and time-consuming manual manipulations in which human error and contamination can be introduced.(Toner \& Irimia, 2005) Therefore, there is increasing interest in downscaling these conventional tasks within LOCs devices and developing novel systems for preparing and detecting the tested samples "on chip". To this aim, integrated microfluidic systems have recently received much attention. However, their technological development requires the miniaturization of analytical techniques and the integration of multiple microcomponents with different functionalities onto the same chip. These integrated microfluidic systems would offer the possibility of reducing time and costs, as well as increasing throughput and automation.

To realize integrated, multifunctional LOCs, two main approaches can be pursued. The first one involves the fabrication of miniaturized functional units and their assembly level by level to achieve desired functionalities. Indeed, microfluidic devices have planar structures 
that can be easily integrated with mechanical, electronic, fluid functions and optical elements (Balslev et al., 2006; Verpoorte, 2003a) According to this approach, a great variety of microfabrication techniques have been developed for manufacturing microfluidic networks integrating advanced functions, such as pumps,(Laser \& Santiago, 2004) valves,(Oh \& Ahn, 2006) mixers,(Nguyen \& Wu 2005) membranes,(de Jong et al., 2006) reactors(McCalla \& Tripathi, 2011) and heating and cooling elements.(Chen et al., 2007) The discussion on the lab-on-chip technologies is beyond the scope of this review and the readers are addressed on recent reviews.(Abgrall \& Gué, 2007; Fiorini \& Chiu, 2005; Ng et al., 2002; Craighead, 2006) Several papers are also available on the integration of some laboratory tasks, including sample pre-processing(C.-Y. Lee et al., 2005; Kraly et al., 2009; Abdelgawad et al., 2009) and pre-concentration,(S. Song \& Singh, 2006; Anson et al., 2006) filtration and separation,(Broyles et al., 2003; Freira \& Wheeler, 2006) as well as fluorescence staining,(S.D.H. Chan et al., 2003; Buhlmann et al., 2003) chemical processing and analysis.(Sims \& Allbritton, 2007)

A great variety of microchip fabrication techniques and materials are available for producing highly sophisticated two- and three-dimensional microstructures with integrated modules.(Erikson \& D. Li, 2004) However, techniques developed to date according to this approach generally require complicated control systems and are by far from being trivial.

The second approach to achieve multifuctional LOCs is recently emerging and consists in incorporating stimuli-responsive hydrogels into microfluidic devices, to obtain smart functional components and simple, highly controllable systems.

Stimuli-responsive hydrogels are polymers demonstrating considerable changes in properties in response to small variations of environmental conditions. To date a variety of polymers have been developed that are sensitive to environmental and biochemical stimuli, including light, $\mathrm{pH}$, temperature, electric and magnetic fields, chemical analytes and biological components.(S.-k. Ahn et al., 2008; Kumar et al., 2007; Chaterji et al., 2007)

The use of an external stimulus in LOC systems is appealing because it can be applied precisely in different sections within a microdevice, thus allowing the microfluidic functions to be integrated in a geometrical confinement. Finally, stimuli-responsive hydrogels have many of the advantages of polymeric materials, such as high response to weak stimuli, versatility, low cost, and compatibility with biological media.

In general, the formation of covalent or non-covalent bonds upon applying a certain stimulus induces changes in polymer chain's conformation. This could lead to some consequences such as the increase/reduction of both pore size and permeability to analytes, as well as significant changes in volume and hydrophilic/hydrophobic properties. These switching properties might be exploited to introduce into the chip "on-demand" changes in volume, permeability and surface chemistry, which in turn activate different functions such as the capability of molecular recognition (including capture, release and detection of biomolecules), autonomous flow rate and wettability switching. It is noteworthy that light and electric field are particularly attractive as stimuli for lab-on-chip applications, since they allow tight control with both high spatial and temporal resolution.

Multiresponsive surfaces are also appealing in microfluidics because they mimic the cooperativity of responsive systems found in nature.(Pasparakisa \& Vamvakaki, 2011) 


\subsection{How to integrate smart polymers into microfluidics - The need of downscaling to micro/nano size}

In the development of hydrogel-based microfluidic devices, an important issue is to downscale the hydrogel size up to micro- or nano-meter scale. This enables not only to obtain components with size comparable to that of microchannels, but above all to overcome the diffusion limitations suffered by larger hydrogels. Indeed, the hydrogel response is typically driven by diffusion of ions and molecules through the polymer network, according to the Donnan equilibrium. The time scales for the volumetric change is highly dependent on the distance of diffusion or the size of the hydrogel, therefore a decrease in hydrogel size at the micro/nanoscale can enhance the hydrogel response time up to few seconds or subseconds,(Eichenbaum et al., 1998; S.K. De et al., 2002) with interesting applications in microfluidic device.(Peppas et al., 2006)

Smart polymers have been essentially deposited as thin films(Tokarev \& Minko 2009) and colloidal particles(Malmstadt et al., 2003, 2004; Peterson, 2005) on solid surfaces for microfluidics. Hydrogel structures have been mainly patterned using photolithographic approaches similar to those employed in semiconductor industry.(Ebara et al., 2006; Khademhosseini \& Langer, 2007; Seong et al., 2002) On the other hand, colloidal particles are excellent candidates for the fabrication of stimuli-responsive surfaces and coatings.

A great variety of applications would ideally take advantage of the unique properties of such smart surfaces. Some examples include microfluidic flow control, (bio)sensors, microscale chromatographic separation, solid-phase extraction, biological assays, and cell culture.

The idea of this review is to present and discuss recent trends in the development of stimuliresponsive polymers for the design and fabrication of multi-integrated microfluidic devices. This review is structured in four major parts, which correspond to the main functions of smart polymers in integrated microfluidic devices: "Smart polymers as actuators", "Smart polymers as sensors", "Controlled absorption and release of (bio)molecules" and "Wetting properties of the microchannels". Finally, a paragraph is dedicated to summarize the immobilization methods of smart polymers and the structural forms by which they are used in microfluidic systems.

\section{Smart polymers as actuators}

Due to their switching properties, stimuli-responsive polymers act as elementary machines (actuators), able to convert environmental signals into a mechanical response. Their ability to undergo abrupt volumetric changes in response to the surrounding environment without the requirement of external power sources provides the polymeric integrated microfluidic components to be autonomous. To date, the autonomous functionality of these components has been achieved by exploiting mainly volume changes exhibited by $\mathrm{pH}$ - and temperatureresponsive hydrogels.

Microfluidic actuators can be divided in those having micromechanical properties, such as microvalves, micromixers, and micropumps, and micro-optical properties, such as microlenses. 


\subsection{Micropumps and micromixers}

In microfluidic systems, micromixers and micropumps are essential components for fluidic handling. Even though numerous designs and materials have been developed,(S.-H. Chiu et al., 2009; S.-M. Ha et al., 2009; Graf \& Bowser, 2008; Tovar \& A.P. Lee, 2009) many of these systems require on-chip power and costly and time-consuming fabrication processing.

In general, micropumps can be classified as either mechanical or non-mechanical. Mechanical micropumps need physical actuators or mechanisms to achieve pumping; they include electrostatic, piezoelectric, thermopneumatic and electromagnetic type.

Non-mechanical micropumps have the ability to transform non-mechanical energy into movement, so that the fluid can be driven. They include magnetohydrodynamic, electrohydrodynamic, electroosmotic, electrowetting, bubble type, electrochemical and evaporation-based micropump.(Tay, 2002; Nisar et al., 2008)

A diffusion micropump intended for low performance applications and a displacement pump which provides higher performance, both based on the temperature-sensitive hydrogel poly(N-isopropylacrylamide) (PNIPAAm) have been reported by Ritcher et al. In a diffusion pump, if the swollen PNIPAAm actuator is heated, it shrinks causing the solution to be released into the outlet and generate pumping pressure; when the hydrogel actuator is cooled down, it swells by absorbing the liquid, leading to the deformation of an elastic membrane which acts as pressure accumulator. In displacement micropumps, unlike in diffusion types, the polymeric actuator generates pumping pressure when it is swelled, and the pressure is reduced when the pumping fluid fills the chamber, i.e. when the hydrogel is in the shrunk phase. Generally, these polymeric micropumps have a simple electrothermic control by means of resistive heating elements, which locally heat the thermo-responsive hydrogel. Therefore, they can be easily integrated on lab-on-a-chip devices.(Richter et al., 2009)

Nestler and co-workers reported a micropump chip that employed a hydrogel based on poly(acrylic acid) sodium salt (PAAS) for generating gas molecules by electrolysis. As almost no heat is generated by electrolysis, this pumping principle is well suited for proteinsensing applications. The PAAS hydrogel was used as electrolyte instead of a liquid, and placed on electrodes. Then a voltage was applied to the electrodes, leading to gas generation by electrolysis. The generated gas was directly used to drive liquids through the channel system in a well-controlled manner.(Nestler et al., 2010)

Micropumps with simple structures and actuated by hydrogel drying have been demonstrated by Choi and co-workers. After exposure to ambient air, the gel block was dehydrated and became absorbent, leading to the suction of the liquid from the connected microchannel and its diffusion into the gel. As a result of the negative pressure, the liquid sample flowed through the microchannel. This kind of pump finds application in microchips that need slow but stable and long-lasting actuation, as well as in sampling proteins from viscous liquids such as blood without filtration or centrifugation.(Y.H. Choi et al., 2009)

Good et al. described a fluid-responsive micropump, which was activated by the addition of water to fluid-responsive polymeric particles. The addition of water induces a significant particle volume expansion and pushes a stored fluid from an adjacent reservoir at a 
predicted flow rate. The experiments were run on two particle systems to investigate how polymer properties can affect the rate and amount of fluid delivered. (Good et al., 2004)

Temperature-sensitive micropumps or micromixers, based on the concept of recirculation and able to autonomously decide when to pump fluid, were developed by Agarwal et al. These systems exploited a poly(HEMA-co-DMAEMA) hydrogel to control a Nickel rotor which could stop pumping as the temperature decreased, whereas for higher temperatures the pumping started. Because of the rotating actuation of the impeller, a change in pressure was induced within the microchannels, thus creating the driving force necessary to pump the liquid.(Agarwal et al., 2005)

An approach aimed to achieve cyclical changes without applying repeated stimuli is based on the use of Belousov-Zhabotinsky (BZ) reaction to control swelling and collapsing of hydrogels in a spatiotemporal manner. The BZ reaction is well known as a non-equilibrium dissipative reaction and generates autonomous oscillations in the redox potential. For example, Murase et al. fabricated gels by copolymerizing temperature-responsive Nisopropylacrylamide with ruthenium tris(2,20-bipyridine) $\left(\mathrm{Ru}(\mathrm{bpy})_{3}\right)$ as the catalyst for the Belousov-Zhabotinsky (BZ) reaction, and obtained autonomous peristaltic motion without external stimuli.(Murase et al., 2008)

Hara and co-workers reported another intriguing approach based on BZ reaction to achieve smart micropumps using a self-oscillating gel actuator, which generates a pendulum motion by fixing one edge of the gel.(Hara \& Yoshida, 2008; Maeda et al., 2008)

Kwon and co-workers reported a valveless micropump system based on the electroactive hydrogel 4-hydroxybutyl acrylate (4-HBA), which shows extremely low energy consumption and high durability. Such pumping system integrated into a compact and portable microfluidic system should represent a promising candidate for an implantable drug delivery system.(G.H. Kwon et al., 2011)
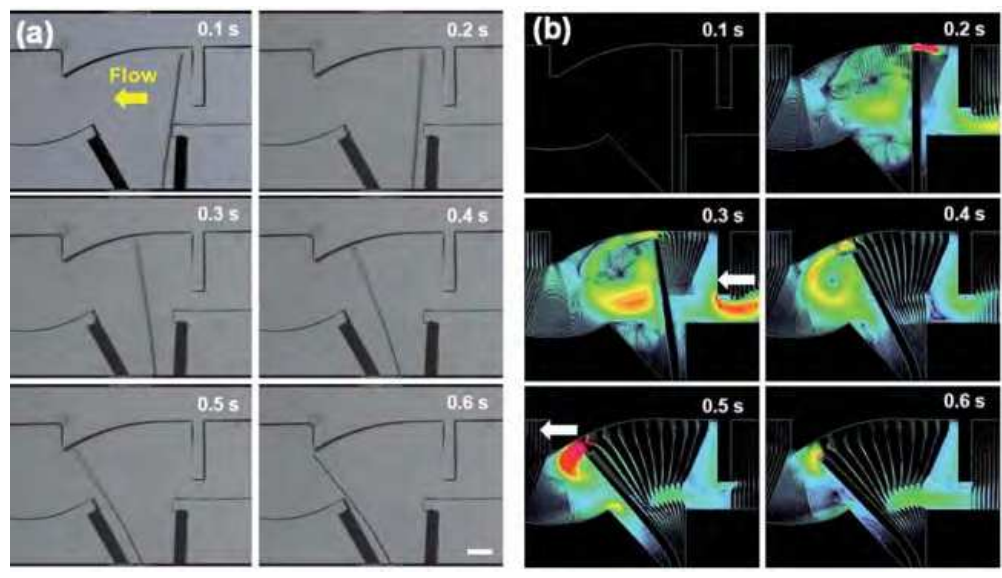

Fig. 2. Sequential photographs showing the gradual development of pumping at $1 \mathrm{~V}$. The scale bar was $500 \mu \mathrm{m}$. (b) microchannel shapes and control signals were simulated using computational fluid dynamics (CFD) analysis to improve the hydrodynamic performance. At $0.3 \mathrm{~s}$ and $0.5 \mathrm{~s}$, arrowheads indicate strong flow. Reprinted from (G.H. Kwon et al., 2011). 


\subsection{Microvalves}

Valves are one of the most crucial components for flow control in microfluidic systems. A conventional active valve consists of a deformable diaphragm coupled to an actuator that controls the on/off state. Micrometer-scale valves, more commonly known as microvalves, can offer important advantages over macroscale valves, as they can operate using small sample volumes, providing rapid response time and low power consumption.

The mechanical or electrical control of these systems relies on their intrinsic responsiveness to thermal, chemical, or electroptical stimuli. Therefore, smart polymers show promising ways of flow control for microfluidic devices based on stimuli-responsive properties.(Dong \& Jiang, 2007; Eddington \& Beebe, 2004) A number of hydrogel microvalves have been developed to date. For example, stimuli-responsive membranes with valve function have been reviewed by Yang et al.(Yang et al., 2011) Membrane valves were realized as a combination of a rigid porous membrane with a soft stimuli-responsive hydrogel, either by depositing a thin layer on the top surface of membrane or by suitable functionalization of the pores. The specific topology - hydrogel on top of or within the porous barrier - was important for the type of on/off response, as shown in Fig. 3.

(a)
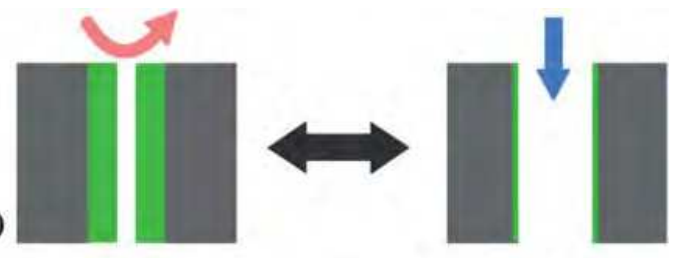

(b)
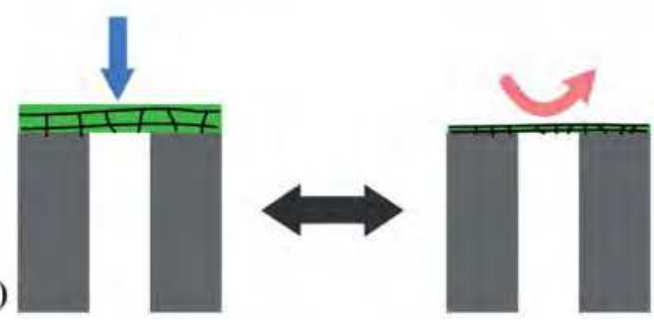

Fig. 3. Schematic overview on two types of membrane valves with stimuli-responsive hydrogel layer at different locations: (a) layer on the pore wall (hydrogel deswelling leads to increasing permeability); (b) crosslinked layer on the top of membrane covering the pore (hydrogel deswelling leads to decreasing permeability). Reprinted from (Yang et al., 2011)

Thus, the selection of the appropriate hydrogel can lead to the design of membranes responsive to different stimuli such as temperature, $\mathrm{pH}$, light, and magnetic forces.

Geiger et al. presented a highly functional microfluidic device exhibiting an integrated thermally sensitive hydrogel valve. The valve was normally closed at room temperature. Upon heating above the lower critical solution temperature (LCST) of $32^{\circ} \mathrm{C}$, the polymer valve became hydrophobic, shrank and formed large pores, thus allowing the solution to flow.(Geiger et al., 2010) 
Chunder et al. developed a superhydrophobic/hydrophilic switchable surface through the combination of layer-by-layer self-assembly and microfabrication techniques. This smart surface realized in a microfluidic channel could therefore act as thermosensitive valve able to control fluid flow by changing the temperature.(Chunder et al., 2009)

Chen et al. developed a light-actuated microvalve by photoinitiated patterned polymerization of NIPAAm within microfluidic channels. In contrast to conventional microvalves activated by heater elements, the novelty of this system relies on heating from the absorption of light provided by a quartz halogen illuminator. The mechanical strength and the resistance to pressure of these microvalves can be tuned by properly choosing the amount of monomer and crosslinker.(G. Chen et al., 2008)

Electronically controllable microvalves based on temperature sensitive hydrogel actuators have been described by Richter et al. Because of the direct placement into the channel, the elastic properties of the hydrogel actuator were exploited to improve the pressure insensitivity, achieve high particle tolerance and avoid a leakage flow.(Richter et al., 2003) However, the utility of electrically driven hydrogel actuators is severely limited in some applications by biocompatibility issues and hydrolytic bubbles generation when the electric field strength exceeds 1.2 V. In particular, bubbles distort the electrical ion flux and degrade the fidelity of the system. To prevent this problem, Kwon and co-workers implemented an electro-responsive hydrogel sorter based on 4-Hydroxybutyl acrylate (4-HBA), which was able to operate at low driving voltages.(G.H. Kwon et al., 2010)

Beebe et al. designed and realized microvalves by either patterning a $\mathrm{pH}$-sensitive hydrogel along the walls of a channel or creating an array of the same hydrogel inside the microfluidic devices. The swelling of these hydrogel structures blocked a channel when a high $\mathrm{pH}$ solution flowed into the channel, whereas when the $\mathrm{pH}$ value was appropriately decreased, the contracted state of hydrogel allowed the fluid to pass.(Beebe et al., 2000; R.H. Liu et al., 2002) Kim et al. developed a hydrodynamic fabrication method for $\mathrm{pH}$-responsive microspheres housed in a PDMS-based microfluidic valve, as reported in Fig. 4. The analysis of volume-changes by alternating application of acidic and basic solutions showed a large and fast volume transition, which was stable and reproducible even under repeated motions.(D. Kim et al., 2007)

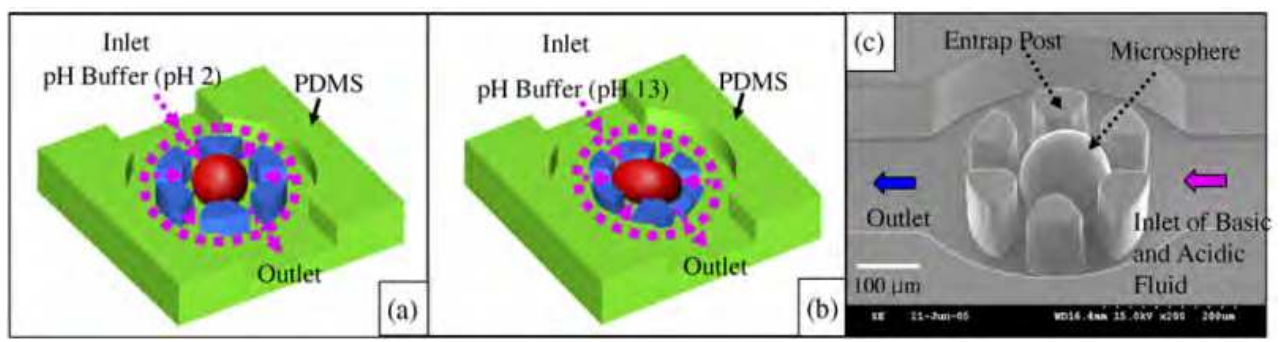

Fig. 4. (a) Conceptual schematic (three-dimensional) of the shrinking motion of the microsphere inside the entrap posts (valve is in the "On" state). (b) Conceptual schematic (three dimensional) of the swelling motion inside the entrap posts (valve is in the "Off" state). (c) SEM image of the microsphere positioned inside the entrap posts. Reprinted from (D. Kim et al., 2007) 


\subsection{Microlenses}

Micro-optical components such as microlenses have been recently benefited from the use of stimuli-responsive hydrogels. In contrast to traditional optical systems, microlenses based on smart polymers have the potential to allow for autonomous focusing without the need for mechanical parts, and above all to achieve a higher degree of integration with other optical components. To date, microlenses have been developed that are actuated by hydrogels responsive to temperature, $\mathrm{pH}$ and light. Dong and his colleagues constructed smart liquid microlenses able to adjust their shape and focal length by taking advantage of temperature and $\mathrm{pH}$-responsive hydrogels. Microlenses were integrated into the chip by filling the microchannel with water and oil, so that the water-oil interface formed the microlens, and placing a stimulus-sensitive hydrogel ring between a glass plate and an aperture ring. The hydrogel ring was able to control the curvature and the focal length of the water-oil meniscus upon environmental changes.(Dong \& Jiang, 2007a, 2007b; Dong et al., 2006)

Gold-PNIPAAm nanocomposites have been also demonstrated to be tunable light-sensitive microlenses. In an attractive demonstration, multiple micropost structures of goldPNIPAAm hydrogels were patterned around a lens aperture. The hydrogel swelling state was controlled by IR light irradiation, which in turn changed the curvature of liquid-liquid interface and, thus, the focal length of the lens. Light controlled microlenses have the potential to replace current technology that uses mechanical or electrical signals.(Zeng \& Jiang, 2008)

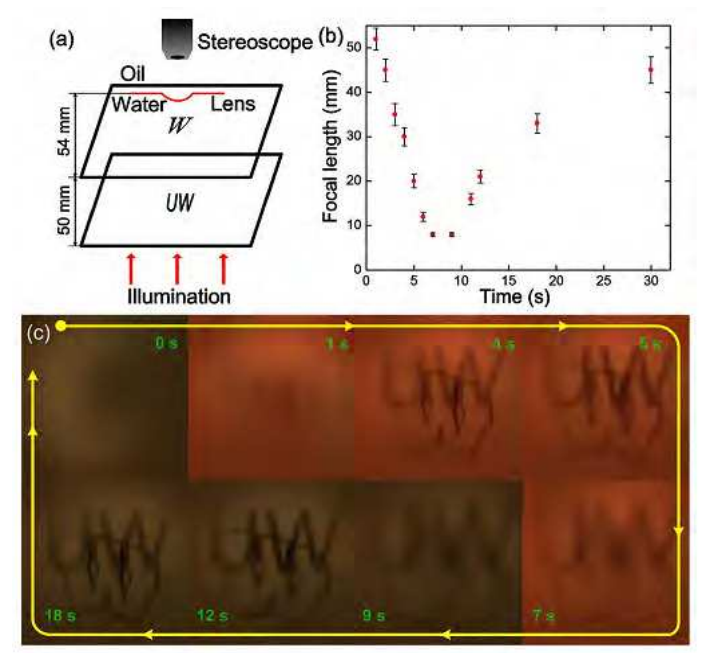

Fig. 5. (a) Schematic of scanning image planes using a liquid tunable microlens. Two logos, $\mathrm{W}$ and UW, are printed on transparency films and are 54 and $104 \mathrm{~mm}$, respectively, below the glass substrate with the microlens. A CCD-coupled stereoscope is placed above the microlens to monitor and record the images. (b) Dynamic change in the positive focal length of the microlens (convergent) in one scanning cycle as a function of time. (c) Frame sequence of the focused images in one scanning cycle obtained by tuning the microlens. Reprinted from (Zeng \& Jiang, 2008). 


\section{Smart polymers as sensors}

A biosensor can be viewed as a combination of a selective detection/recognition unit, a transducing unit and a readout part. The detection unit is designed to react in the presence of the desired analyte. The function of the transducing part of the biosensor is to convert the presence of the relevant analyte into a measured output.(Sugiura et al., 2009) Transduction systems can be divided in three categories: electrochemical, mechanical and optical.

Within the field of biosensors, hydrogels have been applied for two main purposes: to increase the loading capacity of an analyte, and/or to take advantage of hydrogel specific properties including swelling volume, weight, mechanical properties, and refractive index.

Electrochemical sensors represent an important subclass of chemical sensors in which an electrode is used as the transduction element. In this case, hydrogels are mainly exploited as supports for biomolecules, to increase the loading capacity or to stabilize the embedded bioactive material on electrode surface.(Heller, 2006; B. Yu et al., 2008) Some examples of electrochemical sensors are reported in literature. Fernandez-Barbero et al. exploited crosslinked PAA microgels to immobilize Glucose Oxidase (GOx), and studied the modifications induced by the enzyme in the microstructure of the microgels. The use of microgels with entrapped GOx as biological component of an amperometric biosensor allowed evaluating the enzymatic activity of the GOx entrapped in the polymer network. The electrode was prepared by depositing microgel particles on the surface of a platinum electrode, which was then covered with a dialysis membrane to fix the microgels to the electrode.(FernandezBarbero et al., 2009) Huang et al. realized an affinity biosensor based on changes of dielectric properties of a polymer in response to its specific, reversible binding with an analyte. The approach is demonstrated using a synthetic polymer with specific affinity to glucose. The presence of glucose in the tested solution induces changes in the permittivity of the polymer, which can be correlated with specific glucose detection.(X. Huang et al., 2010) Hydrogels of ferrocene-modified acrylamide(Calvo et al., 1993) and poly(vinyl pyridine) containing an osmium complex to electrically wire GOx to carbon electrodes(Gregg \& Heller, 1991) were also developed.

Sridhar \& Takahata reported a wireless device based on $L-C$ circuitry that consists of a variable inductor and a fixed capacitor, coupled with a poly(vinyl alcohol)-poly(acrylic acid) hydrogel for biomedical and chemical sensing.( Sridhar \& Takahata, 1993)

A recent and comprehensive review reported on electroconductive hydrogels, polymeric blends or co-networks (that combine inherently conductive electroactive polymers with highly hydrated hydrogels) and their applications as biorecognition membranes for implantable biosensors.(Guiseppi-Elie, 2010)

Mechanical transducing systems which involve stimuli-responsive polymers exploited changes in volume, weight, mechanical properties and distribution of mechanical stresses. These changes occurring in polymer materials in response to either chemical/physical stimuli or binding events are converted into readable electrical signals. Most studies have been conducted on polymers in an equilibrium state at constant pressure. Under such conditions, the hydrogel polymeric network can expand freely to accommodate an imbalance in osmotic pressure between the inside and the outside of the gel and reach a new equilibrium state. However, if the gel is encapsulated inside a solid structure, the polymer network will exert a pressure over its casing.(I.S. Han et al., 2002) 
Guenther and co-workers realized chemical sensors containing PNIPAAm-based hydrogels as chemo-mechanical transducers. To this aim, thermo-shrinking photo cross-linkable polymers were deposited onto the backside of commercially available pressure sensor chips with a flexible thin silicon membrane. The hydrogel swelling leads to a bending of the silicon membrane and a therefore to an electrical output signal.(Guenther et al., 2007, 2008)

Trinh et al. reported the time-dependent response of a chemo-mechanical sensor by placing a $\mathrm{pH}$-responsive hydrogel to the backside of a piezoresistive membrane, and estimated the degree of hydrogel constraint within the sensor.(Trinh et al., 2006)

A new type of sensor which combines piezoresistive-responsive elements as mechanoelectrical transducers and the phase transition behaviour of hydrogels as a chemomechanical transducer has been recently developed. The sensor consists of a $\mathrm{pH}$-responsive poly(acrylic acid)/poly(vinyl alcohol) (PAA/PVA) hydrogel and a standard pressure sensor chip.(Sorber et al., 2008; Trinh et al., 2006)

Herber et al. presented a sensor based on a pH-sensitive hydrogel for the detection of carbon dioxide gas inside the stomach, in order to diagnose gastrointestinal ischemia.(Herber et al., 2003, 2004, 2005a, 2005b)

Further, a novel hydrogel piezoresistive sensor array has been developed for in vitro monitoring of $\mathrm{pH}$, ionic strength, and glucose concentration. The sensor consists of three components: hydroxypropyl methacrylate (HPMA), N,N-dimethylaminoethyl methacrylate (DMA) and the crosslinker tetra-ethyleneglycol dimethacrylate (TEGDMA) hydrogel. (G. Linet al., 2009; Orthner et al., 2010a, 2010b)

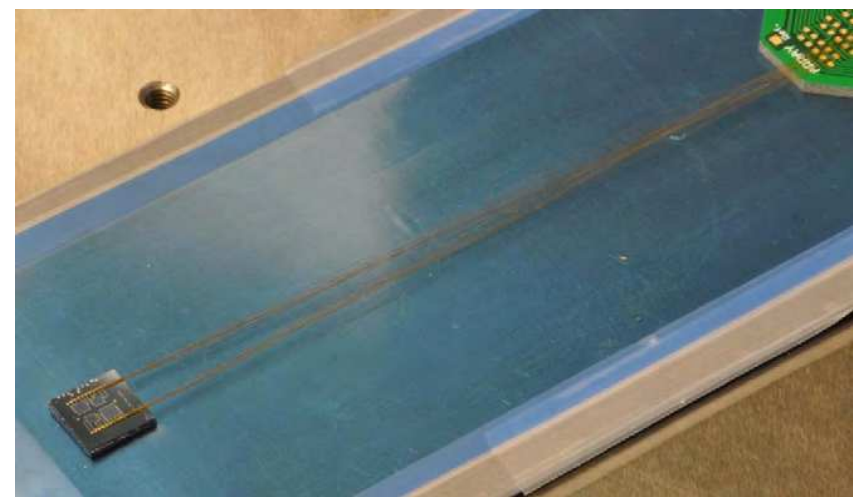

Fig. 6. Photograph of topside of a solid diaphragm sensor assembly with hydrogel inserted and mounted to a perforated backing plate (out of view). Wire bonding was performed using gold insulated wire $(\mathrm{d}=50 \mu \mathrm{m})$. Reprinted from (Orthner et al., 2010b)

Tierney et al. bound a hydrogel to the tip of an optical fiber constituting the environmental sensing element for high-resolution detection. When light was sent through the fiber, it was reflected at the fiber-gel and gel-solution interfaces. The interference wave generated by reflected light enabled the detection of the optical path length within the gel and therefore the degree of gel swelling. These sensors were used in solutions of varying ionic strength and $\mathrm{pH}$, showing a good reproducibility and resolution in the millimolar range.(Tierney et al., 2008) 
(a)

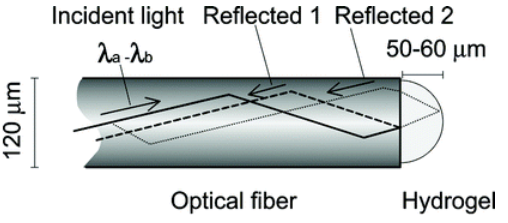

(b)

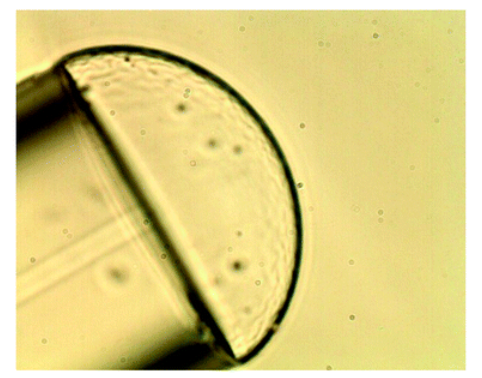

Fig. 7. (a) Schematic illustration of the instrumental technique. The incident light (wavelength range $\lambda_{\mathrm{a}}-\lambda_{\mathrm{b}}$ from 1530 to $1560 \mathrm{~nm}$ ) sent through the optical fiber (diameter 120 $\mu \mathrm{m}$ ) is reflected at both the fiber-gel (reflected 1) and the gel-solution (reflected 2) interfaces. The interference wave is the basis for the measuring technique. The hydrogel covalently linked to the end of the optical fiber adopts a near half-spherical geometry with radius of the order 50-60 $\mu \mathrm{m}$. (b) Micrograph of a polymerized gel attached to a fiber. Reprinted from (Tierney et al., 2008)

Recently, great interest has been shown in surface plasmon resonance (SPR) techniques to detect small changes in refractive indexes close to metallic surfaces. In these systems, changes in the volume density of the hydrogel due to interaction between the analyte and the polymeric network affect the refractive index at the interface.

Huang et al. implemented evanescent wave affinity biosensors based on hydrogel binding matrix for ultra-sensitive detection of molecular analytes. Highly swollen carboxylated poly(N-isopropylacryamide) (NIPAAm) hydrogel was grafted to a sensor surface, functionalized with antibody recognition elements and employed for immunoassay-based detection of target molecules in the tested sample. Molecular binding events were detected by long range surface plasmon (LRSP) and hydrogel optical waveguide (HOW) fieldenhanced fluorescence spectroscopy. The results demonstrated that the analyte detection was improved by properly design the hydrogel structure.(C.J. Huang et al., 2010)

Hydrogels have been also integrated in microlenses for biosensor application. In the system described by Kim and co-workers, microlenses are formed by direct absorption of microgel on a substrate surface; upon absorption, the microgel adopts a lens shape. Changes in the hydrogel swelling affect the shape of the lens and, hence, its focal length. Microlenses made of poly(N-isopropylacrylamide-co-acrylic acid) (PNIPAAm-co-AAc) were properly functionalized to detect antibody-antigen binding, which resulted in an increased local refractive index of the hydrogel matrix. The change in optical properties of the gels can be measured qualitatively: first by the appearance of 'dark rings' in the lenses and second by using the hydrogel lenses to focus a square image; the higher the concentration of analytes, the larger the increase in refractive index, the more focused the image.(J. Kim, 2006, 2007) 


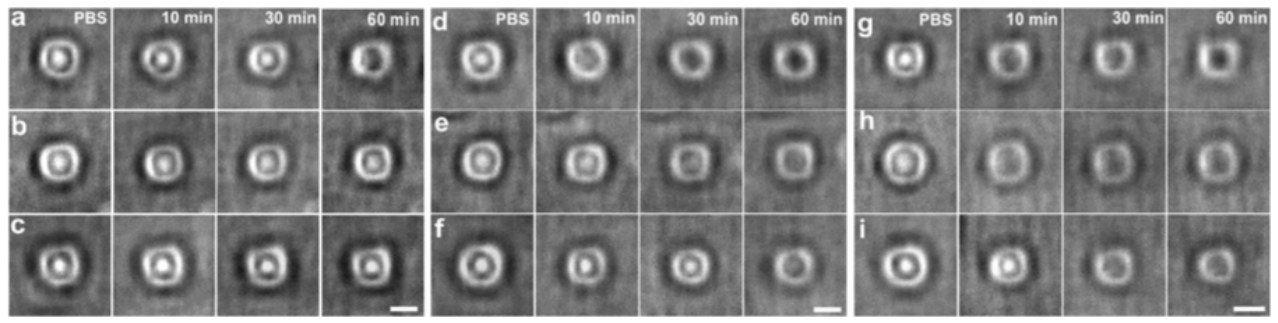

Fig. 8. Microlens response as a function of sensitivity (i.e., bound antibody concentration). Microlens were incubated and photo-cross-linked in anti-biotin solutions with concentrations of $0.7 \mu \mathrm{M}$ (top row a, $\mathrm{d}, \mathrm{g}$ ), $1.0 \mu \mathrm{M}$ (middle row $\mathrm{b}, \mathrm{e}, \mathrm{h}$ ), and $2.0 \mu \mathrm{M}$ (bottom row $\mathrm{c}, \mathrm{f}, \mathrm{i})$. Contact times are indicated at the top of each column, with the initial image in PBS shown in the first column. The scale bar is $2 \mu \mathrm{m}$. Reprinted from (J. Kim, 2007)

Asher and co-workers have developed attractive approaches to make hydrogel based sensors. In one example, they realized a 3-D polymerized colloidal crystal array (PCCA) containing hydrogel sensing units functionalized with molecular recognition agents to detect analytes such as creatinine,(Sharma et al., 2004) glucose,(Alexev et al., 2004) pH,(K. Lee \& Asher, 2000) and organo-phosphorus compounds.(Walker \& Asher, 2005; Tokarev \& Minko, 2010) Afterwards, they reported a new sensing approach that exploited 2-D monolayer arrays of particles attached to molecular recognition polymer hydrogel networks. The 2-D array of photonic crystals, because the hydrogel network swells or shrinks in response to analyte concentration changes, enables to visually identify and quantitate chemical species inside the sample.(K. Lee \& Asher, 2011)

\section{Controlled absorption/release of (bio)molecules within microfluidic devices}

In the development of integrated microfluidics, it is very appealing the miniaturization of multiple components able to achieve separation, purification, and delivery of (bio)molecules on-demand. For instance, many emerging LOC systems - including protein and cell analyses - usually require the reversible, controlled absorption and release of both chemical analytes and biomolecules. Accordingly, the development of active coatings for the uptake and release of (bio)molecules on-chip in response to external stimuli would provide novel functionalities within microdevices towards fully automated LOC systems for sophisticated biomedical analyses.

To this aim, smart polymers have found many applications in microfluidic systems due to hydrophilicity and biocompatibility properties, a wide range of available polymeric materials and the relative ease of chemical modification. Indeed, hydrophilic smart polymers, once immobilized on a solid support, form a soft three-dimensional (3D) matrix able to encapsulate bioactive molecules, provide them with a protective environment and preserve their native status. Above all, they are appealing for microfluidics because of their ability to change their volume and permeability in response to environmental stimuli, which makes them able to encapsulate and release biomolecules on demand, as well as to separate or detect the target analytes.(Peppas et al., 2006) 
However, in the development of microfluidic diagnostics, only few works reported the use of stimuli-responsive polymers for the encapsulation and release of (bio)molecules.

For example, the functionalization of microchannel walls with smart polymers could lead to reversible hydrophilic-hydrophobic surfaces, which allows the physical or covalent immobilization of biomolecules such as proteins. This property has been exploited to integrate protein separation/pre-concentration on chip. Huber et al. developed a microfluidic device in which proteins were adsorbed from solution with negligible denaturation, and released on demand. The key element in this device was an end-tethered monolayer of PNIPAM, which was thermally activated from a hydrophilic state to a hydrophobic, high protein adsorbing state. The PNIPAM film was realized by in situ polymerization onto surfaces previously functionalized with silane coupling agents. Further, heating/cooling transitions were controlled by realizing an array of gold or platinum heater lines deposited onto a silicon nitride membrane.(Huber et al., 2003)

The immobilization of biomolecules by means of stimuli-responsive coating would also allow the implementation of smart protein nanoarrays with well-defined size, shape and interfeature spacing. In particular, Hyun et al. fabricated elastin-like polypeptide (ELP) nanostructures grafted onto $\omega$-substituted thiolates, which in turn were patterned onto gold surfaces by dip-pen nanolithography. These structures underwent a reversible hydrophilichydrophobic phase transition in response to environmental changes such as temperature or ionic strength. According to this phase transition behaviour, two different proteins, namely a thioredoxin-ELP fusion protein and its related monoclonal antibody, were surfacecaptured, thus forming a nanoarray.(Hyun et al., 2004)

It is noteworthy that switchable hydrophilic-hydrophobic surfaces have been employed to capture and release not only biomolecules, but also smart nanobeads carrying stimuliresponsive polymers on the surface. Malmstadt et al. described an interesting approach to graft temperature responsive PNIPAM onto the nanobeads, which underwent a temperatureinduced phase transition from hydrophilic to hydrophobic. The nanobeads were blocked into a microchannel using temperatures above the lower critical solution temperature (LCST), whereas they were released and detected upon applying lower temperatures.(Malmstadt et al., 2003,2004 ) The flexibility of this system allowed the reversible immobilization of biomolecules for separation and detection in microfluidic devices. Several applications of smart nanobeads include microfluidic affinity chromatography and diagnostic immunoassays. Similarly, Ebara et al. functionalized nanobeads with both stimuli-responsive polymers and affinity moieties, such as antibodies. Further, microchannel walls were modified with suitable stimuliresponsive polymers, to ensure a more selective and efficient capture of functionalized nanobeads. (Ebara et al., 2006)

Micro- and nano-particles represent one of the most promising systems for the uptake and release of biomolecules in microfluidics. Thanks to their high surface area per unit volume, they ensure enhanced transport and binding properties.(Verpoorte, 2003a) Nowadays, microparticles have been mainly deposited as close-packed monolayers using layer-by-layer $(\mathrm{LbL})$ assembly for uptake and release of biomolecules and therapeutics. Several instances of LbL multilayer films are reported in literature.(Lynn, 2006; L. Wang et al., 2008; Serpe et al., 2004) Films containing microgels can be swollen in response to external stimuli, which can facilitate the incorporation of guest materials within their polymer network. For example, a new type of microgels of poly(allylamine hydrochloride) (PAH) and dextran (D) was 
alternatively deposited with polyanion poly(styrene sulfonate) (PSS) by Wang et al., to produce multilayer films of PAH-D/PSS able to reversibly load and release negatively charged guest materials. The PAH-D microgel could be deposited on both hydrophilic and hydrophobic surfaces, such as quartz, polytetrafluoroethylene, polystyrene, etc. without any substrate modification. (L. Wang et al., 2008)

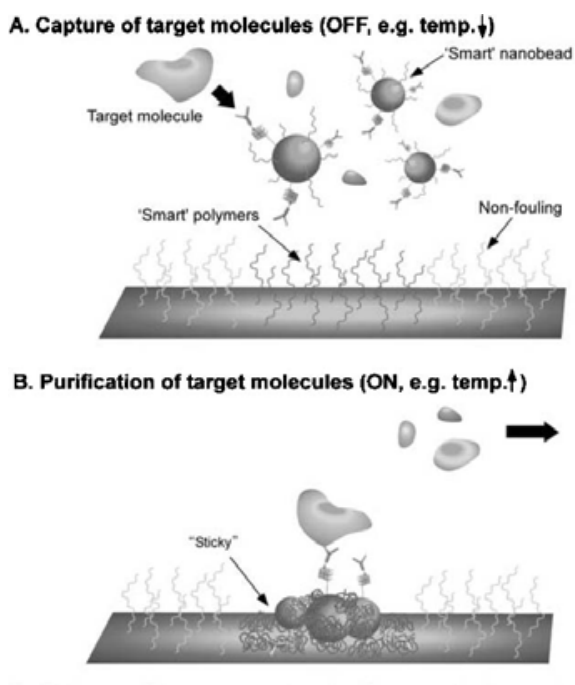

C. Release of the target molecules for quantitative analysis. (OFF, e.g. temp. .)

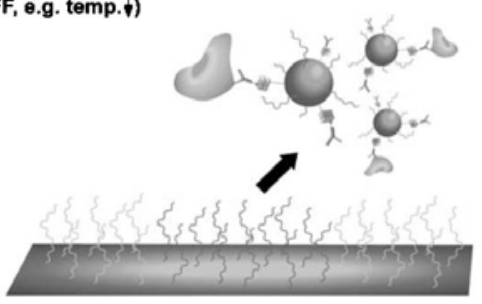

Fig. 9. Design concept for smart microfluidic system that utilizes smart nanobeads.

Reprinted from (Ebara et al., 2006)

A functional use of microgels in LOCs requires that they have to be fixed within the active regions of the device channels and not flow out during the analysis. Therefore, we recently reported a novel method for in situ $\mathrm{pH}$-controlled cell staining by means of covalently immobilized poly(methacrylic acid) (PMAA) microgels. The PMAA microgels were synthesized in solution and covalently immobilized on a glass substrate previously modified with an organosilane agent and an amine-terminated PEG. The immobilized PMAA microgels preserved their $\mathrm{pH}$-sensitivity, thus making them suitable for the $\mathrm{pH}$ controlled uptake of an oligothiophene-conjugated anti-human CD4 monoclonal antibody (MAb). This smart support was incubated with a Jurkat T-cell suspension, the physiological $\mathrm{pH}$ of the extracellular environment induced the release of the labeled MAbs, and the highly selective staining of the CD4-positive subpopulations within the Jurkat cell suspension was demonstrated by confocal microscopy.(Argentiere et al., 2009) 


\section{Wetting properties of the microchannels}

Smart polymers are key elements to achieve switching wettability in microfluidics. When the proper stimulus is applied, they undergo a a reversible change from hydrophilic to hydrophobic, resulting in the wettability switching on a properly engineered surface. This reversible transition might be exploited in many applications, such as cell detachment and cell harvesting, and to produce self-cleaning membranes/filters within microdevices. An intriguing approach to realize switchable hydrophilic-hydrophobic surfaces has been developed in the past years and consists in grafting smart polymers onto chemically modified surfaces. Actually, the most exploited stimuli in the development of such smart coatings are temperature and light.

\subsection{Thermoresponsive wettability}

Poly(N-substituted) acrylamides are still being the most investigated family of thermoresponsive polymers. Their temperature-sensitive behaviour has been widely investigated and is dependent on the formation of intramolecular hydrogen bonds between $\mathrm{C}=\mathrm{O}$ and $\mathrm{N}-\mathrm{H}$ groups in polymer chains.(G. Chen \& Hoffman, 1995) Poly(N,N'-diethyl acrylamide) (PDEAAm), poly(N-(DL)-(1-hydroxymethyl) propylmethacrylamide) (P(DL)HMPMA), poly(dimethylaminoethyl methacrylate) (PDMAEMA) and poly(N-vinyl caprolactone) (PVCL) exhibit lower critical solution temperature (LCST) in a range of 25$32^{\circ}, 35^{\circ}, 50^{\circ}$ and $35^{\circ} \mathrm{C}$ respectively.(Idziak et al., 1999; Qiu \& Park, 2001; F. Liu \& Urban, 2008; Aoki et al., 2001) However, poly(N-isopropylacrylamide) (PNIPAAm) is still being the most studied in the family of poly(N-substituted acrylamide), especially in biomedical applications, due to its sharp transition range as well as the close proximity of its LCST (around $32^{\circ} \mathrm{C}$ ) to physiologically relevant temperatures. To date, the most common method for grafting PNIPAAm on inert microchannel surfaces such as silicon, glass, gold and polystyrene is the benzophenone-initiated photopolymerization.(D. Ma et al., 2009) Cheng et al. developed PNIPAAm based microheaters, able to carry out a selective protein binding as a function of temperature. They demonstrated that PNIPAAm films switched between adhesive and non-adhesive under the control of individual heaters. This localized change in the surface adhesive behaviour has been used to direct site-specific cell attachment. $(X$. Cheng et al., 2004) Further, the thermo-switchable hydrophobic/hydrophilic properties of PNIPAAm-grafted-PDMS microchannels has been exploited to develop novel techniques for cell detachment at room temperature and without trypsin digestion.(D. Ma et al., 2010)

Wetting properties have significant effects on liquid behaviour in microfluidic systems.(Handique et al., 1997) In general, a surface effect is the basis of both valve and pump functions.(Delamarche et al., 1997) Thus, the modification of channel walls with smart, reversible polymers leads to useful properties, such as reversible hydrophilichydrophobic surfaces, and to the development of novel microcomponents with actuating functions. (Idota et al., 2005, 2006). These applications are described in details in Section 1.

It is important to highlight that the switchable wettability of PNIPAAm grafts, in particular for multiscale micro- and nano-structures, is closely related to the substrate roughness. The introduction of rough structures into micro-areas is difficult, for this reason the enhancement of PNIPAAm performance on flat substrates, especially for applications at the microscale, represents an important challenge. For example, Fu et al. grafted PNIPAAm 
onto porous anodic aluminum oxide. The obtained nanostructured surfaces were demonstrated to undergo simultaneous changes in roughness and wettability by varying the temperature.(Fu et al., 2004) Finally, Sun and Qing reported that the behaviour of PNIPAAm brushes are significantly affected by the grafting density on the surface. To this aim, they introduced inert molecules, such as heptadeca-fluorodecyltrimethoxysilane, onto the surfaces, to dilute the initiator concentration in the atom-transfer radical polymerization (ATRP) process.(Sun et al., 2005)

\subsection{Photoresponsive wettability}

The approach of photoresponsive wettability relies on the use of photochromic molecules able to undergo reversible changes in their polarity when irradiated at specific light wavelength. For instance, Caprioli et al. demonstrated that the wettability of microchannels functionalized by cyclic olefin copolymers can be switched by irradiation. Such characteristic can be exploited to enhance the flow rate of fluids in microfluidic channels by on-off valve behaviour, allowing or blocking the liquid filling process on the base of optical control.(Caprioli et al., 2007) The reversible photoswitchable wettability of organic nanofibers based on 1',3'-dihydro-1',3',3'-trimethyl-6-nitrospiro[2H-1-benzopyran-2,2'-(2H)indole] has been studied by Di Benedetto and co-workers. The switching properties of the nanofibers were investigated by studying the evolution of absorbance with different UV exposure times, photoluminescence lifetime, cyclic photoisomerization, and reversible wettability.(Di Benedetto et al., 2008) Athanassiou and co-workers prepared a nanopatterned spiropyran-doped polymer surface and observed the impact of surface roughness on surface wettability by alternation of UV and green laser irradiation.(Athanassiou et al., 2006) The contact angle (CA) changes were amplified on the nanopatterned grating surface, and either surface hydrophobicity or hydrophilicity was enhanced on an optimized pattern size. Spiropyran-based responsive surfaces have also attracted much attention in the exploration of stimuli-responsive surface wettability. Rosario et al. used a photoresponsive spiropyran monolayer to coat a silicon nanowire surface. Upon irradiation from UV $(366 \mathrm{~nm})$ to visible wavelengths $(450-550 \mathrm{~nm})$, the CA increased to $23^{\circ}$ from $12^{\circ}$ on the flat surface.(Rosario et al., 2004)

\section{Immobilization methods}

In microfluidic applications, smart polymers must be kept within the channel and not flushed out during analysis. Accordingly, a multitude of approaches have been developed to introduce and fix them into microfluidic devices. Ideally, smart polymers should be fixed using cheap, robust and reliable methods.

Photopolymerization has been successfully used for smart polymers immobilization. For example, multiple photopolymerized gel patches have been prepared within a microchannel, and each patch can be used as a $\mathrm{pH}$ sensor or to analyze enzymatic activity.(Zhan et al., 2002; Q.M. Zhang et al., 2002) PNIPAM hydrogels have been also photopolymerized in microfluidic channels, resulting in the fabrication of thermally responsive devices.(Kuckling et al., 2002; Harmon et al., 2003)

To date, smart polymers have been employed in microfluidic systems in different forms such as particles, films, membranes, fibers and monoliths. Micro- and nano-particles have 
been used extensively in microfluidics to produce or enhance surface coatings.(Verpoorte, 2003b) Colloidal particles have been also suspended in the medium to obtain logic control.(L. Wang et al., 2010) Actually, there are essentially two methods in order to keep fixed the beads within a microfluidic device. According to the first one, smart microparticles are trapped within a chamber on the microfluidic device. The second method involves immobilizing beads onto a surface, typically using self-assembly methods, such as layer-bylayer (LbL), and covalent immobilization.(Peterson, 2005) For instance, functionalized microparticles may be fixed onto surfaces using hydrophobic/hydrophilic interactions or assemblies of oligonucleotides.(T.T. Huang et al., 2003; McNally et al., 2003) A number of different methods have been reported for trapping particles into a microdevice, some using physical barriers to retain beads, others using magnetic fields to manipulate and trap beads.(Linder et al., 2002; J.-W. Choi et al., 2001) An interesting entrapment method is reported in the previous section by Malmstadt et al.(Malmstadt et al., 2003, 2004) As reported by Andersson et al., a series of pillars could constrain beads placed in a microfluidic chip and this approach was useful in fabricating devices for single-nucleotide polymorphism analysis and capillary electrochromatography.(Andersson et al., 2000)

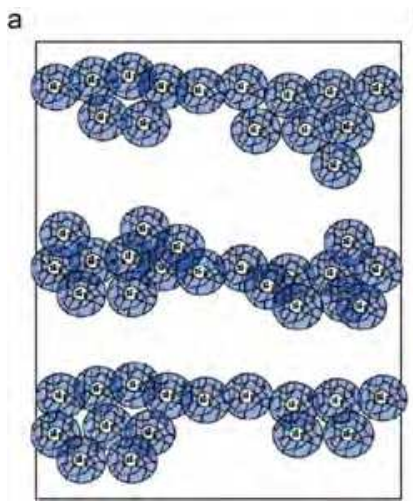

b

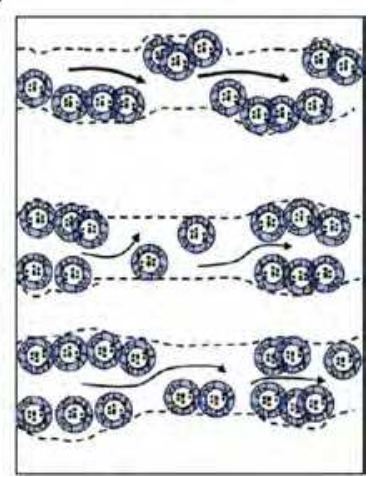

Fig. 10. Schematic representation of channels made of magnetic polystyrene latex covered with PNIPAAm and built in the PVA gel matrix: (a) "off" state below the collapse transition temperature; (b) "on" state above the collapse transition temperature. (Kumar et al., 2007)

As alternative to particles, smart polymers may be placed within microfluidic systems as films. Multilayer films of smart polymers with precise control of thickness and composition are fabricated generally by LbL deposition, a very versatile and convenient method.

The electrodeposition is another technique for the immobilization of films onto the conducting part of the surface, with the additional benefit of spatially selective cathode patterning (electropatterning).(Shacham et al., 1999)

Alternative smart polymeric supports for separating and detecting biomolecules in microfluidic systems are stimuli-responsive membranes.(Xue et al., 2008; Wandera et al., 2010) They are characterized by pores that can open and close by electronic induced stimuli such as electric or magnetic fields.(Csetneki et al., 2006) Membranes incorporating specific recognition elements after detecting the presence of a specific substance or a specific stimulus were able to translate this signal into a change of physico-chemical properties (i.e., 
changes in the permeability).(Kumar et al., 2007) Smart hydrogel membranes functionalized with enzymes can recognized glucose, which in turn actuates other stimuli-mediated changes (e.g., $\mathrm{pH}$ in the case of GOx-mediated glucose degradation).(Chaterji et al., 2007) Biocatalytic systems containing stimuli-responsive hydrogel membranes represent another promising approach for the uptake and release of biomolecules and drugs by receiving and processing the biochemical information.(Tokarev, 2009)

Stimuli-responsive electrospun fibers represent appealing and highly versatile tools for microfluidic devices.(Dalton et al., 2002; Jeong et al., 2004) Cylindrical polymeric structures composed of smart polymers can be employed for the encapsulation and detection of biomolecules.(C. Huang et al., 2011) Different kinds of smart fibers can be obtained, depending on the responsive polymers used. Jeong et al. fabricated fibers by employing 3-D multiple stream laminar flow and "on the fly" photopolymerization.(Tao, 2011)

Smart polymers have been also placed within porous monoliths.(Svec et al., 2003) Monoliths have been fabricated in specific areas of a microchip via photolithographic techniques based on UV-initiated polymerization methods.(Peterson et al., 2003) Smart gels and polymer monoliths have been shown to be very versatile in producing microfluidic systems. (Peterson, 2005) For instance, NIPAM was incorporated into the monolith and polymerized to realize temperature-responsive systems.(C. Yu et al., 2003)

\section{Conclusion}

Today, there is a growing need to integrate biological and chemical tasks within microfluidic devices, in order to achieve multifunctional systems. An overview of the applications of stimuli-responsive polymers in microfluidics literature is here presented. Stimuli responsive polymers, also known as "smart" polymers, have recently found many applications in integrated microfluidic systems due to their properties, a wide range of available polymeric materials and the relative ease of chemical synthesis. Modification of the channel walls with smart polymers leads to multilayers structure capable to encapsulate and release (bio)molecules on demand, undergo micromechanical changes for actuating and sensing functions, modify the wetting properties of the microchannels to realize for example valving elements, and generally integrate many functions in one chip, thus producing "smart" multifunctional devices.

\section{References}

Abdelgawad, M., Watson, M.W.L., Wheeler, A.R. (2009). Hybrid microfluidics: A digital-tochannel interface for in-line sample processing and chemical separations. Lab Chip, Vol. 9, No. 8, pp. 1046-1051.

Abgrall P., Gue', A.-M. (2007). Lab-on-chip technologies: making a microfluidic network and coupling it into a complete microsystem-a review. J. Micromech. Microeng., Vol. 17, pp. R15-R49.

Agarwal, A.K., Sridharamurthy, S.S., Beebe, D.J. (2005). Programmable Autonomous Micromixers and Micropumps. Journal of Microelectromechanical Systems, Vol. 14, pp. 1409-1421.

Ahn, S.-k., Kasi, R.M., Kim, S.-C., Sharma, N., Zhou, Y. (2008). Stimuli-responsive polymer gels. Soft Matter, Vol. 4, pp. 1151-1157. 
Alexeev, V.L., Das, S., Finegold, D.N. \& Asher, S.A. (2004). Photonic Crystal GlucoseSensing Material for Noninvasive Monitoring of Glucose in Tear Fluid. Clin. Chem., Vol. 50, pp. 2353 - 2360.

Andersson, H., van der Wijngaart, W., Enoksson, P. \& Stemme, G. (2000). Micromachined flow-through filter-chamber for chemical reactions on beads. Sensors and Actuators B: Chemical, Vol. 67, No. 1-2, pp. 203-208.

Anson V. Hatch, Herr, A.E., Throckmorton, D.J., Brennan, J.S., Singh, A.K. (2006). Integrated Preconcentration SDS-PAGE of Proteins in Microchips Using Photopatterned Cross-Linked Polyacrylamide Gels. Anal. Chem., Vol. 78, pp. 4976-4984.

Aoki, T., Muramatsu, M., Torii T., Sanui K. and Ogata N. (2001).Thermosensitive phase transition of an optically active polymer in aqueous milieu. Macromolecules, Vol. 34, pp. 3118-3119.

Argentiere, S., Blasi, L., Ciccarella, G., Cazzato, A., Barbarella, G., Cingolani, R., Gigli, G. (2009). Smart surfaces for $\mathrm{pH}$ controlled cell staining. Soft Matter, Vol. 5, No. 21, pp. 4101-4103.

Athanassiou, A., Lygeraki, M.I., Pisignano, D., Lakiotaki, K., Varda, M., Mele, E., Fotakis, C., Cingolani, R. \& Anastasiadis, S.H. (2006). Photocontrolled Variations in the Wetting Capability of Photochromic Polymers Enhanced by Surface Nanostructuring. Langmuir, Vol. 22, pp. 2329- 2333.

Balslev, S., Jorgensen, A.M., Bilenberg, B., Mogensen, K. B., Snakenborg, D., Geschke, O., Kutter, J.P., Kristensen, A. (2006) Lab-on-a-chip with integrated optical transducers. Lab Chip, Vol. 6, pp. 213-217.

Beebe, D.J., Moore, J.S., Bauer, J.M., Yu, Q., Liu, R.H., Devadoss, C., Jo, B.-H. (2000). Functional hydrogel structures for autonomous flow control inside microfluidic channels. Nature, Vol. 404, No. 6778, pp. 588-590.

Beebe, D.J., Mensing, G.A., Walker, Glenn M. (2002) Physics and applications of microfluidics in biology. Annu. Rev. Biomed. Eng., Vol. 4, pp. 261-286.

Broyles, B.S., Jacobson, S.C., Ramsey, J.M. (2003). Sample Filtration, Concentration, and Separation Integrated on Microfluidic Devices. Anal. Chem., Vol. 75, pp. 2761-2767.

Buhlmann, C., Preckel, T., Chan, S., Luedke, G., Valer, M. (2003). A New Tool for Routine Testing of Cellular Protein Expression: Integration of Cell Staining and Analysis of Protein Expression on a Microfluidic Chip-Based System. Journal of Biomolecular Techniques, Vol. 14, No. 2, pp. 119-127.

Calvo, E.J., Danilowicz, C. \& Diaz. L.J. (1993). Enzyme catalysis at hydrogel-modified electrodes with redox polymer mediator. Chem. Soc. Faraday Trans., Vol. 89, pp. 377384.

Caprioli, L., Mele, E., Angile, F.E., Girardo, S., Athanassiou, A., Camposeo, A., Cingolani, R. \& Pisignano, D. (2007). Photocontrolled wettability changes in polymer microchannels doped with photochromic molecules. Applied Physics Letters. Vol. 91, pp. 113113-3.

Chan, S.D.H., Luedke, G., Valer, M., Buhlmann, C., Preckel, T. (2003). Cytometric Analysis of Protein Expression and Apoptosis in Human Primary Cells With a Novel Microfluidic Chip-Based System. Cytom. Part A, Vol. 55A, pp. 119-125.

Chaterji, S., Kwon, I.K., Park, K. (2007). Smart Polymeric Gels: Redefining the Limits of Biomedical Devices. Prog. Polym. Sci., Vol. 32, No. 8-9, pp. 1083-1122. 
Chen , G., Hoffman, A.S. (1995). Graft copolymers that exhibit temperature-induced phase transitions over a wide range of pH. Nature, Vol. 373, pp. 49 - 52.

Chen, G., Svec, F., Knapp, D.R. (2008). Light-actuated high pressure-resisting microvalve for on-chip flow control based on thermo-responsive nanostructured polymer. Lab Chip, Vol. 8, No. 7, pp. 1198-1204.

Chen, L., Manz, A., Day, P.J.R. (2007) Total nucleic acid analysis integrated on microfluidic devices. Lab Chip, Vol. 7, No. 11, pp. 1413-1423.

Cheng, X., Wang, Y., Hanein, Y., Böhringer, K.F. \& Ratner, B.D. (2004). Novel cell patterning using microheater-controlled thermoresponsive plasma films. J. Biomed. Mater. Res. A., Vol. 70, No. 2, pp. 159-168.

Chiu, S.-H., Liu, C.-H. (2009). An air-bubble-actuated micropump for on-chip blood transportation. Lab Chip, Vol. 9, No. 11, pp. 1524-1533.

Choi, J.-W., Oh, K. W., Han, A., Wijayawardhana, C. A., Lannes, C., Bhansali, S., Schlueter, K. T., Heineman, W. R., Halsall, H. B., Nevin, J. H., Helmicki, A. J., Henderson, H. T. \& Ahn, C. H. (2001). Development and characterization of microfluidic devices and systems for magnetic bead-based biochemical detection. Biomedical Microdevices, Vol. 3, No. 3, pp. 191-200.

Choi, Y.H., Chung, K.H.; Lee, S.S. (2009). Microfluidic actuation by dehydration of hydrogel. Sensors, 2009 IEEE, pp.1370 - 1373.

Chunder, A., Etcheverry, K., Londe, G., Cho, H.J., Zhai, L. (2009). Conformal switchable superhydrophobic/ hydrophilic surfaces for microscale flow control. Colloids and Surfaces A: Physicochemical and Engineering Aspects, Vol. 333, No. 1-3, pp. 187-193.

Craighead, H. (2006). Future lab-on-a-chip technologies for interrogating individual molecules. Nature, Vol. 442, pp. 387-393.

Csetneki, I., G. Filipcsei, \& M. Zrínyi (2006). Smart Nanocomposite Polymer Membranes with On/Off Switching Control. Macromolecules, Vol. 39, No. 5, pp. 1939-1942.

Dalton, P. D., Flynn, L. \& Shoichet, M. S. (2002). Biomaterials, Vol. 23, pp. 3843.

De, S.K., Aluru, N. R., Johnson, B., Crone, W.C., Beebe, D.J., Moore, J. (2002). Equilibrium Swelling and Kinetics of pH-Responsive Hydrogels: Models, Experiments, and Simulations. Journal of Microelectromechanical systems, Vol. 11, No. 5, pp. 544 - 555.

de Jong, J., Lammertink, R.G., Wessling, M. (2006). Membranes and microfluidics: a review. Lab Chip, Vol. 6, pp. 1125-1139.

Delamarche, E., Bernard, A., Schmid, H., Michel, B. \& Biebuyck H. (1997). Patterned delivery of immunoglobulins to surfaces using microfluidic networks. Science Vol. 276, pp. 779-781.

Di Benedetto, F., Mele, E., Camposeo, A., Athanassiou, A., Cingolani, R. \& Pisignano, D. (2008). Photoswitchable organic nanofibers. Adv. Mater., Vol. 20, pp. 314.

Dittrich, P.S., Manz, A. (2006). Lab-on-a-chip: microfluidics in drug discovery. Nature, Vol. 5 , pp. 210-218.

Dong, L., Agarwal, A.K., Beebe, D.J., Jiang, H. (2006). Adaptive liquid microlenses activated by stimuli-responsive hydrogels. Nature, Vol. 442, No. 7102, pp. 551-554.

Dong, L., Jiang, H. (2007a). Autonomous microfluidics with stimuli-responsive hydrogels. Soft Matter, Vol. 3, No. 10, pp. 1223-1230.

Dong, L., Jiang, H. (2007b). Variable-Focus Liquid Microlenses and Microlens Arrays Actuated by Thermo-responsive Hydrogels. Adv. Mater., Vol. 19, No. 3, pp. 401-405. 
Ebara, M., Hoffman, J.M., Hoffman, A.S., Stayton, P.S. (2006). Switchable surface traps for injectable bead-based chromatography in PDMS microfluidic channels. Lab Chip, Vol. 6, No. 7, pp. 843-848.

Eddington, D.T., Beebe, D.J. (2004). Flow control with hydrogels. Adv. Drug Deliv. Rev., Vol. 56, No. 2, pp. 199-210.

Eichenbaum, G.M.. Kiser, P.F., Simon S.A., Needham, D. (1998). pH and Ion-Triggered Volume Response of Anionic Hydrogel Microspheres. Macromolecules, Vol. 31, pp. 5084-5093.

Erickson, D. \& Li, D. (2004). Integrated microfluidic devices. Analytica Chimica Acta, Vol. 507, pp. 11-26.

Fernández-Barbero, A., Suárez, I.J., Sierra-Martín, B., Fernández-Nieves, A., de las Nieves F.J., Marquez, M., Rubio-Retama, J. \& López-Cabarcos, E. (2009) Gels and microgels for nanotechnological applications. Adv. Colloid Interface Sci., Vol. 147-148, pp.88108.

Fiorini, G.S., Chiu, D.T. (2005). Disposable microfluidic devices: fabrication, function, and application. BioTechniques, Vol. 38, pp. 429-446.

Freirea, S.L.S., Wheeler, A.R. (2006). Proteome-on-a-chip: Mirage, or on the horizon? Lab Chip, Vol. 6, pp. 1415-1423.

Fu, Q., Rao, G.V.R., Basame, S.B., Keller, D.J., Artyushkova, K., Fulghum, J.E., López, G.P. (2004). Reversible Control of Free Energy and Topography of Nanostructured Surfaces J. Am. Chem. Soc., Vol. 126, pp. $8904-8905$.

Geiger, E.J., Pisano, A.P., Svec, F. (2010). A Polymer-Based Microfluidic Platform Featuring On-Chip Actuated Hydrogel Valves for Disposable Applications. J. Microelectromech. Systems, Vol. 19, No. 4, pp. 944-950.

Good, B.T., Bowman, C.N., Davis, R.H. (2004). Modeling and verification of fluid-responsive polymer pumps for microfluidic systems. Chemical Engineering Science, Vol. 59, No. 24, pp. 5967-5974.

Graf, N.J., Bowser, M.T. (2008). A soft-polymer piezoelectric bimorph cantilever-actuated peristaltic micropump. Lab Chip, Vol. 8, No. 10, pp. 1664-1670.

Gregg, B.A. \& Heller, A. (1991) Redox polymer films containing enzymes. 2. Glucose oxidase containing enzyme electrodes. J. Phys. Chem., Vol. 95, pp. 5976-5980.

Guenther, M., Kuckling, D., Corten, C., Gerlach, G., Sorber, J., Suchaneck, G. \& Arndt, K.F. (2007). Chemical sensors based on multiresponsive block copolymer hydrogels. Sensors \& Actuators: B. Chemical, Vol. 126, pp. 97-106.

Guenther, G.G., Corten, C., Kuckling, D., Sorber, J. \& Arndt, K.F. (2008). Hydrogel-based sensor for a rheochemical characterization of solutions. Sensors and Actuators B: Chemical, Vol. 132, pp. 471-476.

Guiseppi-Elie, A. (2010) Electroconductive hydrogels: synthesis, characterization and biomedical applications Biomaterials, Vol. 31, pp. 2701-2716.

Ha, S.-M., Cho, W., Ahn, Y. (2009). Disposable thermo-pneumatic micropump for bio lab-ona-chip application. Microelectron. Eng., Vol. 86, No. 4-6, pp. 1337-1339.

Han, I.S., Han, M.-H., Kim, J., Lew, S., Lee, Y.J., Horkay, F. \& Magda, J.J. (2002) Constantvolume hydrogel osmometer: a new device concept for miniature biosensors. Biomacromolecules, Vol. 3, pp. 1271-1275. 
Handique K., Gogoi, .B.P., Burke, D.T., Mastrangelo, C.H. \& Burns, M.A. (1997). Microfluidic flow control using selective hydrophobic patterning. Proc. SPIE, Vol. 3224, pp. 185-95.

Hara, Y., Yoshida, R. (2008). Self-Oscillating Polymer Fueled by Organic Acid. J. Phys. Chem. B, Vol. 112, No. 29, pp. 8427-8429.

Harmon, M.E., Tang, M. \& Frank, C.W. (2003). A microfluidic actuator based on thermoresponsive hydrogels. Polymer, Vol. 44, No. 16, pp. 4547-4556.

Heller, A., (2006). Electron-conducting redox hydrogels: design, characteristics and synthesis Curr. Opin. Chem. Biol., Vol.10, pp. 664-672.

Herber, S., Olthuis, W. \& Bergveld, P. (2003). A swelling hydrogel-based PCO2 sensor. Sensors E Actuators: B. Chemical, Vol. 91, pp. 378-382.

Herber, S., Olthuis, W., Bergveld, P. \& Van Den Berg, A. (2004). Exploitation of a pHsensitive hydrogel disk for CO2 detection. Sensors \& Actuators: B. Chemical, Vol. 103, pp. 284-289.

Herber, S., Borner, J., Olthuis, W., Bergveld, P. \& Van Den Berg, A. (2005a). A micro CO2 gas sensor based on sensing of $\mathrm{pH}$-sensitive hydrogel swelling by means of a pressure sensor. Transducers, Vol. 2, pp. 1146-1149.

Herber, S., Bomer, J., Olthuis, W., Bergveld, P. \& Van Den Berg, A. (2005b). A miniaturized carbon dioxide gas sensor based on sensing of $\mathrm{pH}$-sensitive hydrogel swelling with a pressure sensor. Biomedical Microdevices, Vol. 7, pp. 197-204. http://www.yole.fr/

Huang, C., Soenen, S.J., Rejman, J., Lucas, B., Braeckmans, K., Demeester J. \& De Smedt S.C. (2011). Stimuli-responsive electrospun fibers and their applications. Chem. Soc. Rev., Vol. 40, pp. 2417-2434.

Huang C.J., Dostalek, J. \& Knoll, W. (2010). Long range surface plasmon and hydrogel optical waveguide field-enhanced fluorescence biosensor with 3D hydrogel binding matrix: On the role of diffusion mass transfer Biosens. Bioelectron., Vol. 26, pp. 1425-1431.

Huang, X., Li, S., Schultz, J.S., Wang, Q. \& Lin, Q. (2010). A dielectric affinity microbiosensor. Appl. Phys. Lett., Vol. 96, pp. 033701.

Huang, T.T., Geng, T., Akin, D., Chang, W.-J., Sturgis, J., Bashir, R., Bhunia, A.K., Robinson, J.P. \& Ladisch, M.R. (2003). Micro-assembly of functionalized particulate monolayer on C18-derivatized $\mathrm{SiO} 2$ surfaces. Biotechnology and Bioengineering, Vol. 83, No. 4, pp. 416-427.

Huber, D.L., Manginell, R.P., Samara, M.A., Kim, B.-I. \& Bunker, B.C. (2003). Programmed Adsorption and Release of Proteins in a Microfluidic Device. Science, Vol. 301, pp. 352-354.

Hyun, J., Lee, W.-K., Nath, N., Chilkoti, A. \& Zauscher, S. (2004). Capture and Release of Proteins on the Nanoscale by Stimuli-Responsive Elastin-Like Polypeptide "Switches". J. Am. Chem. Soc., Vol. 126, pp. 7330-7335.

Idziak, I., Avoce, D., Lessard, D., Gravel, D. \& Zhu, X. X. (1999). Thermosensitivity of Aqueous Solutions of Poly(N,N-diethylacrylamide). Macromolecules, Vol. 32, pp. 1260-1263

Jeong, W., Kim, J., Kim, S., Lee, S., Mensing, G., Beebe, D. J. (2004). Lab Chip, Vol 4, pp. 576.

Khademhosseini, A. \& Langer, R. (2007). Microengineered hydrogels for tissue engineering. Biomaterials, Vol. 28, No. 34, pp. 5087-5092. 
Kim, D., Kim, S., Park, J., Baek, J., Kim, S., Sun, K., Lee, T., Lee, S. (2007). Hydrodynamic fabrication and characterization of a $\mathrm{pH}$-responsive microscale spherical actuating element. Sensors and Actuators A: Physical, Vol. 134, No. 2, pp. 321-328.

Kim, J., Singh, N. \& Lyon, L.A. (2006). Label-Free Biosensing with Hydrogel Microlenses. Angew. Chem. Int. Ed., Vol. 45, pp. 1446 -1449.

Kim, J., Singh, N. \& Lyon, L.A. (2007). Displacement-Induced Switching Rates of Bioresponsive Hydrogel Microlenses. Chem. Mater., Vol. 19, pp. 2527-2532.

Kim, S.M., Lee, S.H., Suh, K.Y. (2008) Cell research with physically modified microfluidic channels: A review. Lab Chip, Vol. 8, pp. 1015-1023.

Kraly, J.R., Holcomb, R.E., Qian, G., Henry, C.S. (2009). Review: Microfluidic applications in metabolomics and metabolic profiling. Analytica Chimica Acta, Vol. 653, No. 1, pp. 23-35.

Kumar, A., Srivastava, A., Galaev, I.Y., Mattiasson, B. (2007). Smart polymers: Physical forms and bioengineering applications. Prog. Polym. Sci., Vol. 32, pp. 1205 - 1237.

Kuckling, D., Harmon, M.E. \& Frank, C.W. (2002). Photo-Cross-Linkable PNIPAAm Copolymers. 1. Synthesis and Characterization of Constrained TemperatureResponsive Hydrogel Layers. Macromolecules, Vol. 35, No. 16, pp. 6377-6383.

Kwon, G.H., Choi, Y.Y., Park, J.Y., Woo, D.H., Lee, K.B., Kim, J.H., Lee, S.-H. (2010). Electrically-driven hydrogel actuators in microfluidic channels: fabrication, characterization, and biological application. Lab Chip, Vol. 10, No. 12, pp. 1604-1610.

Kwon, G.H., Jeong, G.S., Park, J.Y., Moon, J.H., Lee, S.-H. (2011). A low-energy-consumption electroactive valveless hydrogel micropump for long-term biomedical applications. Lab Chip, Vol. 11, No. 17, pp. 2910-2915.

Laser, D., Santiago, J.G. (2004) A review of micropumps. J. Micromech. Microeng., Vol. 14, pp. R35-R64.

Lee, C.-Y., Lee, G.-B., Lin, J.-L., Huang, F.-C., Liao, C.-S. (2005). Integrated microfluidic systems for cell lysis, mixing/pumping and DNA amplification. Journal of Micromechanics and Microengineering, Vol. 15, No. 6, pp. 1215-1223.

Lee, K. \& Asher, S.A. (2000). Photonic Crystal Chemical Sensors: pH and Ionic Strength. J. Am. Chem. Soc., Vol. 122, pp. 9534-9537.

Lee, K. \& Asher, S.A. (2011). Photonic Crystal Chemical Sensors: pH and Ionic Strength. J. Am. Chem. Soc., Vol.133, pp. 9152-9155.

Lin, G., Chang, S., Kuo, C.-H., Magda, J. \& Solzbacher, F. (2009). Free swelling and confined smart hydrogels for applications in chemomechanical sensors for physiological monitoring Sens. Actuators, B Chem., Vol. 136, pp. 186-195.

Linder, V., Verpoorte, E., de Rooij, N.F., Sigrist, H. \& Thormann, W.(2002). Application of surface biopassivated disposable poly(dimethylsiloxane)/glass chips to a heterogeneous competitive human serum immunoglobulin $G$ immunoassay with incorporated internal standard. Electrophoresis, Vol. 23, No. 5, pp. 740-749.

Liu, F. \& Urban, M.W. (2008). 3D Directional Temperature Responsive (N-(d)-(1Hydroxymethyl) Propylmethacrylamide-co-n-butyl Acrylate) Colloids and Their Coalescence. Macromolecules, Vol. 41, pp. 352 - 360.

Liu, R.H., Yu, Q., Beebe, D.J. (2002). Fabrication and Characterization of Hydrogel-Based Microvalves. J. Microelectromech. Systems, Vol. 11, No. 1, pp. 45-53.

Lynn, D.M. (2006). Layers of opportunity: nanostructured polymer assemblies for the delivery of macromolecular therapeutics. Soft Matter, Vol. 2, No. 4, pp. 269-273. 
Ma, D., Chen, H.W., Shi, D.Y., Li, Z.M. \& Wang, J.F. (2009). Preparation and characterization of thermo-responsive PDMS surfaces grafted with poly(N-isopropylacrylamide) by benzophenone-initiated photopolymerization. J. Colloid Interface Sci., Vol. 332, pp. 85-90.

Ma, D., Chen, H., Li, Z. \& He, Q. (2010). Thermomodulated cell cultureharvest in polydimethyl-siloxane microchannels with poly(N-isopropylacrylamide)-grafted surface. Biomicrofluidics, Vol. 4, No. 4, pp. 044107.

Maeda, S., Hara, Y., Yoshida, R., Hashimoto, S. (2008). Control of the Dynamic Motion of a Gel Actuator Driven by the Belousov-Zhabotinsky Reaction. Macromolecular Rapid Communications, Vol. 29, No. 5, pp. 401-405.

Malmstadt, N., Yager, P., Hoffman, A.S., Stayton, P.S. (2003). A Smart Microfluidic Affinity Chromatography Matrix Composed of Poly(N-isopropylacrylamide)-Coated Beads. Anal. Chem., Vol. 75, No. 13, pp. 2943-2949.

Malmstadt, N., Hoffman, A.S., Stayton, P.S. (2004). "Smart" mobile affinity matrix for microfluidic immunoassays. Lab Chip, Vol. 4, pp. 412-415.

McCalla, S.E., Tripathi, A. (2011). Microfluidic Reactors for Diagnostics Applications. Annual Review of Biomedical Engineering, Vol. 13, No.1, pp. 321-343.

McNally, H., Pingle, M., Lee, S. W., Guo, D., Bergstrom, D. E. \& Bashir, R. (2003). Selfassembly of micro- and nano-scale particles using bio-inspired events. Applied Surface Science, Vol. 214, No. 1-4, pp. 109-119.

Murase, Y., Maeda, S., Hashimoto, S., Yoshida, R. (2008). Design of a Mass Transport Surface Utilizing Peristaltic Motion of a Self-Oscillating Gel. Langmuir, Vol. 25, No. 1, pp. 483-489.

Neethirajan, S., Kobayashi, I., Nakajima, M., Wu, D., Nandagopal, S., Lin, F. (2011). Microfluidics for food, agriculture and biosystems industries. Lab Chip Vol. 11, pp. 1574-1586.

Nestler, J., Morschhauser, A., Hiller, K., Otto, T., Bigot, S., Auerswald, J., Knapp, H. F., Gavillet, J., Gessner, T. (2010). Polymer lab-on-chip systems with integrated electrochemical pumps suitable for large-scale fabrication. The International Journal of Advanced Manufacturing Technology, Vol. 47, No. 1, pp. 137-145.

Ng, J.M.K., Gitlin, I., Stroock, A.D., Whitesides, G.M. (2002). Components for integrated poly(dimethylsiloxane) microfluidic systems. Electrophoresis, Vol. 23, pp. 3461-3473.

Nguyen, N.-T., Wu, Z. (2005). Micromixers - a review. J. Micromech. Microeng., Vol. 14, pp. R1-R16.

Nisar, A., Afzulpurkar, N., Mahaisavariya, B., Tuantranont, A. (2008). MEMS-based micropumps in drug delivery and biomedical applications. Sensors and Actuators B: Chemical, Vol. 130, No. 2, pp. 917-942.

Oh, K.W., Ahn, C.H. (2006). A review of microvalves. J. Micromech. Microeng., Vol. 16, pp. R13-R39.

Orthner, M.P., Lin, G., Avula, M., Buetefisch, S., Magda, J., Rieth, L.W. \& Solzbacher, F. (2010a). Hydrogel based sensor arrays $(2 \times 2)$ with perforated piezoresistive diaphragms for metabolic monitoring (in vitro). Sens. Actuators, B Chem., Vol. 145, pp. 807-816.

Orthner, M.P., Buetefisch, S., Magda, J., Rieth, L.W. \& Solzbacher, F. (2010b). Development, fabrication, and characterization of hydrogel based piezoresistive pressure sensors with perforated diaphragms. Sensor Actuat. A-Phys. Vol. 161, pp. 29 -38. 
Pasparakisa, G., Vamvakaki, M. (2011). Multiresponsive polymers: nano-sized assemblies, stimuli-sensitive gels and smart surfaces. Polym. Chem., Vol. 2, pp. 1234-1248.

Peppas, N.A., Hilt, J.Z., Khademhosseini, A., Langer, R. (2006). Hydrogels in Biology and Medicine: From Molecular Principles to Bionanotechnology. Adv. Mater., Vol. 18, pp. 1345-1360.

Peterson, D.S., Rohr, T., Svec, F. \& Fréchet, J.M.J. (2003). Dual-function microanalytical device by in-situ photolithographic grafting of porous polymer monolith: integrating solid phase extraction and enzymatic digestion for peptide mass mapping. Analytical Chemistry, Vol. 75, pp. 5328-5335.

Peterson, D.S. (2005). Solid supports for micro analytical systems. Lab Chip, Vol. 5, pp. 132139.

Qiu, Y. \& Park, K. (2001). Environment-sensitive hydrogels for drug delivery. Adv. Drug Delivery Rev., Vol. 53, pp. 321-339.

Richter, A., Kuckling, D., Howitz, S., Gehring, T., Arndt, K. F. (2003). Electronically controllable microvalves based on smart hydrogels: magnitudes and potential applications. J. Microelectromech. Systems, Vol. 12, No. 5, pp. 748-753.

Richter, A., Klatt, S., Paschew, G., Klenke, C. (2009). Micropumps operated by swelling and shrinking of temperature-sensitive hydrogels. Lab Chip, Vol. 9, No. 4, pp. 613-618.

Rosario, R., Gust, D., Garcia, A.A., Hayes, M., Taraci, J.L., Dailey, J.W. \& Picraux, S.T. (2004). Lotus Effect Amplifies Light-Induced Contact Angle Switching. J. Phys. Chem. B, Vol. 108, pp. 12640-12642.

Seong, G.H., Zhan, W., Crooks, R.M. (2002). Fabrication of Microchambers Defined by Photopolymerized Hydrogels and Weirs within Microfluidic Systems: Application to DNA Hybridization. Anal Chem, Vol. 74, No. 14, pp. 3372-3377.

Serpe, M.J., Yarmey, K.A., Nolan, C.M. \& Lyon, L.A. (2004). Doxorubicin Uptake and Release from Microgel Thin Films. Biomacromolecules, Vol. 6, No. 1, pp. 408-413.

Shacham, R., Avnir, D. \& Mandler, D. (1999). Electrodeposition of Methylated Sol-Gel Films on Conducting Surfaces. Advanced Materials, Vol. 11, No. 5, pp. 384-388.

Sharma, A.C., Jana, T., Kesavamoorthy, R., Shi, L., Virji, M.A., Finegold, D. N. \& Asher, S. A. (2004). General photonic crystal sensing motif: creatinine in bodily fluids. J. Am. Chem. Soc., Vol. 126, pp. 2971-2977.

Sia, S.K., Kricka, L.J. (2008). Microfluidics and point-of-care testing. Lab Chip Vol. 8, pp. 1982-1983.

Sims C.E., Allbritton N.L. (2007). Analysis of single mammalian cells on-chip. Lab Chip, Vol. 7, pp. 423-440.

Song, S., Singh,.A.K. (2006). On-chip sample preconcentration for integrated microfluidic analysis. Anal. Bioanal. Chem., Vol. 384, pp. 41-43.

Sorber, J., Steiner, G., Schulz, V., Guenther, M., Gerlach, G., Salzer, R. \& Arndt, K-F. (2008) Hydrogel-based piezoresistive ph sensors: investigations using FT-IR attenuated total reflection spectroscopic imaging. Anal. Chem., Vol. 80, pp. 2957-2962.

Sridhar, V. \& Takahata, K. (2009) A hydrogel-based passive wireless sensor using a flexcircuit inductive transducer. Sensor Actuat A-Phys,. Vol. 155, pp. 58-65.

Sugiura, S., Szilagyi, A., Sumaru, K., Hattori, K., Takagi, T., Filipcsei, G., Zrinyi, M., Kanamori, T. (2009). On-demand microfluidic control by micropatterned light irradiation of a photoresponsive hydrogel sheet. Lab Chip, Vol. 9, No. 2, pp. 196-198. 
Sun, T., Song, W. \& Jiang, L. (2005). Control over the responsive wettability of poly(Nisopropylacrylamide) film in a large extent by introducing an irresponsive molecule. Chem. Commun., pp. 1723 - 725.

Svec, F., Tennikova, T.B. \& Deyl, Z., (May 2003). Monolithic Materials: Preparation, Properties and Applications (Journal of Chromatography Library), Elsevier Science, ISBN-10: 0444508791 ISBN-13: 978-0444508799, Amsterdam.

Tao, X. (2001). Smart fibres, fabrics and clothing: Fundamentals and applications, Woodhead Publishing Ltd, ISBN-10: 1855735466 ISBN-13: 978-1855735460, Hong Kong.

Tay, F. (2002). Microfluidics and BioMEMS Applications (1st edition), Springer, Kluwer Academic Publishers, ISBN 978-1-4020-7237-6, Boston, pp. 3-24.

Tierney, S., Hjelme, D.R. \& Stokke, B.T. (2008). Determination of Swelling of Responsive Gels with Nanometer Resolution. Fiber-Optic Based Platform for Hydrogels as Signal Transducers. Anal. Chem., Vol. 80, pp. 5086-5093.

Tokarev, I. (2009). ACS Appl. Mater. Interfaces, Vol. 1, No. 3, pp. 532-536.

Tokarev, I., Minko, S. (2009). Stimuli-responsive hydrogel thin films. Soft Matter, Vol. 5, No. 3, pp. 511-524.

Tokarev, I. \& Minko, S. (2010). Stimuli-Responsive Porous Hydrogels at Interfaces for Molecular Filtration, Separation, Controlled Release, and Gating in Capsules and Membranes. Adv. Mater., Vol. 22, No. 31, pp. 3446-3462.

Toner, M., Irimia, D. (2005). Blood-on-a-chip. Annu. Rev. Biomed. Eng. Vol. 7, pp. 77-103.

Tovar, A.R., Lee, A.P. (2009). Lateral cavity acoustic transducer. Lab Chip, Vol. 9, No. 1, pp. 41-43.

Verpoorte, E. (2003a) Chip vision - optics for microchips. Lab. Chip, Vol. 3, pp. 42N-52N.

Verpoorte, E. (2003b). Focus Beads and chips: new recipes for analysis. Lab Chip, Vol. 3, No. 4, pp. $60 \mathrm{~N}-68 \mathrm{~N}$.

Trinh, Q.T., Gerlach, G., Sorber, J. \& Arndt, K.-F.(2006). Hydrogel-based piezoresistive pH sensors: design, simulation and output characteristics. Sens. Actuators, B Chem., Vol. 117 pp. 17-26.

Xue, J., Chen, L., Wang, H. L., Zhang, Z. B., Zhu, X. L., Kang, E. T. \& Neoh, K. G. (2008). Stimuli-Responsive Multifunctional Membranes of Controllable Morphology from Poly(vinylidene fluoride)-graft-Poly[2-(N,N-dimethylamino)ethyl methacrylate] Prepared via Atom Transfer Radical Polymerization. Langmuir, Vol. 24, No. 24, pp. 14151-14158.

Yang, Q., Adrus, N., Tomicki, F., Ulbricht, M. (2011). Composites of functional polymeric hydrogels and porous membranes. J. Mater. Chem., Vol. 21, No. 9, pp. 2783-2811.

Yu, B., Wang, Y., Ju, Y.M., West, J.H., Moussy, Y. \& Moussy, F. (2008). Use of hydrogel coating to improve the performance of implanted glucose sensors. Biosens. Bioelectron., Vol. 23, pp. 1278-1284.

Yu, C., Mutlu, S., Selvaganapathy, P., Mastrangelo, C.H., Svec, F. \& Fréchet, J.M. (2003). Flow control valves for analytical microfluidic chips without mechanical parts based on thermally responsive monolithic polymers. Analytical Chemistry, Vol. 75, No. 8, pp. 1958-1961.

Walker, J.P. \& Asher, S.A. (2005). Acetylcholinesterase-Based Organophosphate Nerve Agent Sensing Photonic Crystal. Anal. Chem., Vol. 77, pp. 1596 -1600.

Wandera, D., Wickramasinghe, S. R. \& Husson, S.M. (2010). Stimuli-responsive membranes. Journal of Membrane Science, Vol. 357, No. 1-2, pp. 6-35. 
Wang, L., Wang, X., Xu, M., Chen, D. \& Sun, J. (2008). Layer-by-Layer Assembled Microgel Films with High Loading Capacity: Reversible Loading and Release of Dyes and Nanoparticles. Langmuir, Vol. 24, No. 5, pp. 1902-1909.

Wang, L., Zhang, M., Li, J., Gong, X., Wen, W. (2010). Logic control of microfluidics with smart colloid. Lab Chip, Vol. 10, No. 21, pp. 2869-2874.

Zeng, X., Jiang, H. (2008). Tunable liquid microlens actuated by infrared light-responsive hydrogel. Appl. Phys. Lett., Vol. 93, pp. 151101-3.

Zhan, W., G.H. Seong, \& R.M. Crooks (2002). Hydrogel-Based Microreactors as a Functional Component of Microfluidic Systems. Anal. Chem., Vol. 74, No. 18, pp. 4647-4652.

Zhang, Q.M., Li, H. F., Poh, M., Xia, F., Cheng, Z. Y., Xu, H. S. \& Huang, C. (2002). Nature Vol. 419, pp. 284-287. 


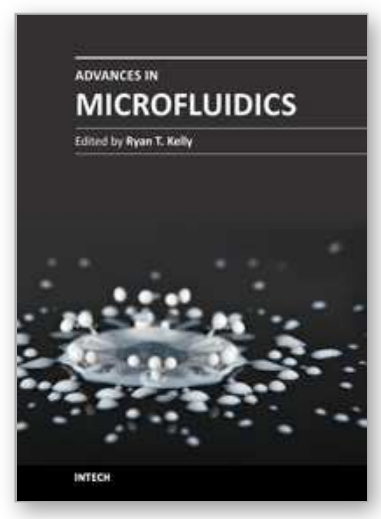

\author{
Advances in Microfluidics \\ Edited by Dr. Ryan Kelly
}

ISBN 978-953-51-0106-2

Hard cover, 250 pages

Publisher InTech

Published online 07, March, 2012

Published in print edition March, 2012

Advances in Microfluidics provides a current snapshot of the field of microfluidics as it relates to a variety of sub-disciplines. The chapters have been divided into three sections: Fluid Dynamics, Technology, and Applications, although a number of the chapters contain aspects that make them applicable to more than one section. It is hoped that this book will serve as a useful resource for recent entrants to the field as well as for established practitioners.

\title{
How to reference
}

In order to correctly reference this scholarly work, feel free to copy and paste the following:

Simona Argentiere, Giuseppe Gigli, Mariangela Mortato Irini Gerges and Laura Blasi (2012). Smart Microfluidics: The Role of Stimuli- Responsive Polymers in Microfluidic Devices, Advances in Microfluidics, Dr. Ryan Kelly (Ed.), ISBN: 978-953-51-0106-2, InTech, Available from:

http://www.intechopen.com/books/advances-in-microfluidics/smart-microfluidics-the-role-of-stimuli-responsivepolymers-in-microfluidic-devices

\section{INTECH}

open science | open minds

\section{InTech Europe}

University Campus STeP Ri

Slavka Krautzeka 83/A

51000 Rijeka, Croatia

Phone: +385 (51) 770447

Fax: +385 (51) 686166

www.intechopen.com

\section{InTech China}

Unit 405, Office Block, Hotel Equatorial Shanghai

No.65, Yan An Road (West), Shanghai, 200040, China

中国上海市延安西路65号上海国际贵都大饭店办公楼 405 单元

Phone: +86-21-62489820

Fax: +86-21-62489821 
(C) 2012 The Author(s). Licensee IntechOpen. This is an open access article distributed under the terms of the Creative Commons Attribution 3.0 License, which permits unrestricted use, distribution, and reproduction in any medium, provided the original work is properly cited. 